\title{
Critical pharmacokinetic and pharmacodynamic drug-herb interactions in rats between warfarin and pomegranate peel or guava leaves extracts
}

Maisa Alnaqeeb', Kenza A. Mansor², Eyad M. Mallah², Bayan Y. Ghanim ${ }^{3}$ Nasir ldkaidek ${ }^{3}$ and Nidal A. Qinna ${ }^{1,3^{*}}$

\begin{abstract}
Background: In-depth information of potential drug-herb interactions between warfarin and herbal compounds with suspected anticoagulant blood thinning effects is needed to raise caution of concomitant administration. The current study aimed to investigate the impact of co-administration of pomegranate peel and guava leaves extracts, including their quality markers namely; ellagic acid and quercetin, respectively, on warfarin's in vivo dynamic activity and pharmacokinetic actions, in addition to potential in vitro cytochrome P450 enzymes (CYP) inhibition.

Methods: Influence of mentioned extracts and their key constituents on warfarin pharmacodynamic and kinetic actions and CYP activity were evaluated. The pharmacodynamic interactions were studied in Sprague Dawley rats through prothrombin time (PT) and International Normalized Ratio (INR) measurements, while pharmacokinetic interactions were detected in vivo using a validated HPLC method. Furthermore, potential involvement in CYP inhibition was also investigated in vitro on isolated primary rat hepatocytes.

Results: Preparations of pomegranate peel guava leaf extract, ellagic acid and quercetin in combination with warfarin were found to exert further significant increase on PT and INR values $(p<0.01)$ than when used alone $(p<0.05)$. Pomegranate peel extract showed insignificant effects on warfarin pharmacokinetics $(p>0.05)$, however, its constituent, namely, ellagic acid significantly increased warfarin $C_{\max }(p<0.05)$. Guava leaves extract and quercetin resulted in significant increase in warfarin $C_{\max }$ when compared to control $(p<0.01)$. Furthermore, guava leaves extract showed a significant effect on changing the AUC, CL and $V_{z}$. Significant reduction in CYP2C8, 2C9, and 3A4 was seen upon concomitant use of warfarin with ellagic acid, guava leaves and quercetin, unlike pomegranate that insignificantly affected CYP activities.

Conclusion: All combinations enhanced the anticoagulant activity of warfarin as the results of in vivo and in vitro studies were consistent. The current investigation confirmed serious drug herb interactions between warfarin and pomegranate peel or guava leaf extracts. Such results might conclude a high risk of bleeding from the coadministration of the investigated herbal drugs with warfarin therapy. In addition, the results raise attention to the blood-thinning effects of pomegranate peel and guava leaves when used alone.
\end{abstract}

Keywords: Drug-herb interactions, Bleeding, Pomegranate peel, Ellagic acid, Guava leaves, Cytochrome P450

\footnotetext{
* Correspondence: nqinna@uop.edu.jo

${ }^{1}$ Department of Pharmacology and Biomedical Sciences, Faculty of Pharmacy

and Medical Sciences, University of Petra, Airport Road, P.O. Box 961343,

Amman, Jordan

${ }^{3}$ University of Petra Pharmaceutical Center (UPPC), University of Petra,

Amman, Jordan

Full list of author information is available at the end of the article
}

(c) The Author(s). 2019 Open Access This article is distributed under the terms of the Creative Commons Attribution 4.0 International License (http://creativecommons.org/licenses/by/4.0/) which permits unrestricted use, distribution, and reproduction in any medium, provided you give appropriate credit to the original author(s) and the source, provide a link to the Creative Commons license, and indicate if changes were made. The Creative Commons Public Domain Dedication waiver (http://creativecommons.org/publicdomain/zero/1.0/) applies to the data made available in this article, unless otherwise stated. 


\section{Background}

The wide spread of using natural products among people raised interest in their therapeutic activity as an alternative medicine. Furthermore, the complex mixture of bioactive constituents makes it important to evaluate potential interactions between natural products and prescribed drugs, especially, when used concomitantly with drugs that have narrow therapeutic index.

Many studies were published evaluating the potential metabolic or pharmacologic interactions between natural products and warfarin. An example of the former includes alteration of vitamin $\mathrm{K}$ bioavailability through some herbs that might inhibit synthesis of vitamin $\mathrm{K}$ by intestinal flora, like thyme and garlic which influence vitamin K-dependent clotting factor synthesis, thereby enhance the effect of warfarin [1]. The most important kinetic interactions are those interfering with warfarin hepatic metabolism. For example, St John's wort induces microsomal cytochrome P450 (CYP) enzyme-mediated metabolism of warfarin, particularly CYP2C9 and increases warfarin clearance [2].

The contribution of bioactive phytochemicals including polyphenols, phytosterols has been raising concern in CYP-associated metabolic studies for potential drug-herb interactions, as the consumption and use of herbal supplements increased in the recent years. Many studies reported the involvement of flavonoids including quercetin, ellagitannins and others in triggering CYP450 enzyme activities [3-6], therefore they have been concerned in the current study. Pomegranate peel (Punica granatum L., Lythraceae) and guava leaves (Psidium guava L., Myrtaceae) extracts are examples of widely used natural products due to their pharmacological actions. Many studies demonstrated that pomegranate peel has anti-diarrheal, anti-ulcerative, antioxidant and anti-inflammatory effects [7-10]. Pomegranate peel is an important source of many bioactive compounds including phenolic compounds like punicalagins, flavonoids like quercetin (Que), ellagitannins such as ellagic acid (EA) and gallic acid [11]. It has been reported that pomegranate peel could possess in vitro thrombolytic activity when added to clots formed from human blood samples, extracts of it were reported to cause prolonged bleeding and thrombin time [12]. In addition to its reported ability to alter Prothrombin time (PT), reduce platelet aggregation and protect against hematotoxicty [13-16].

Guava leaves possess anti-tussive, anti-hypertensive, anti-hyperglycemic and anti-hyperlipidemic activities [1719]. Flavonoids including quercetin and its glycoside are major constituents in guava leaves extract [20]. Anticoagulant properties of guava leaves through its major phytochemicals including gallic acid and quercetin have been also reported [21]. In fact, the presence of quercetin in guava leaves raise the concern of inducing drug-herb interaction between guava and warfarin since quercetin and its metabolites were reported to induce antiplatelet and anticoagulant activities in additon to its interaction of displacing warfarin from its protein binding site [22-24].

Owing to the capacity of such phytochemical compounds in altering the parameters mentioned earlier, this study aimed to investigate the impact of concomitant administration of pomegranate peel and guava leaves extracts, including their quality markers; ellagic acid and quercetin, respectively, on warfarin activity and bioavailability pre clinically in Sprague Dawley rats as a suitable model for warfarin's action. In addition, the potential inhibition of selected CYP enzymes that are responsible for warfarin metabolism is investigated with the herbal drugs in vitro on rat isolated primary hepatocytes.

\section{Methods \\ Materials}

Warfarin, quercetin hydrate and ellagic acid were purchased from Sigma-Aldrich (Missouri, USA). Standardized guava leaves extract (Psidium guava L.) (5\% quercetin) and pomegranate peel extract (Punica granatum L.) (40\% ellagic acid) were obtained from Gehrlicher $\mathrm{GmbH}$ (Eurasburg, Germany), and Puritans Pride (California, USA), respectively.

Carboxy Methyl Cellulose (CMC) was obtained from SciChem (West Midlands, England). For PT test, Néoplastine $^{\circ}$ CI Plus kit (Stago S.A.S, France) was used and tested on semi-automated, dual-channel coagulometer BFT II analyzer (Siemens GmbH, Erlangen, Germany). Tri-sodium citrate $3.2 \%(0.109 \mathrm{~mol} / \mathrm{L})$ and EDTA micro tubes were used to collect blood samples. As for HPLC analysis, deionized water (Nanopur $\left.{ }^{\mathrm{ru}}\right)$, methanol and acetonitrile (Chromanorm ${ }^{\circ}$ ) were obtained from Fisher Scientific Ltd. (Loughborough, UK). Phosphoric acid and triethylamine were purchased from Tedia (California, USA). As for metronidazole benzoate, it was a kind gift from the Jordanian Pharmaceutical Manufacturing Company (Amman, Jordan).

For the isolation of rat primary hepatocytes; Hank's Balanced Salt Solution (HBSS) $\left(\mathrm{Ca}^{2+}\right.$ and $\mathrm{Mg}^{2+}$ free) and HBSS (with $\mathrm{Ca}^{2+}$, and $\mathrm{Mg}^{2+}$ ) were obtained from Invitrogen (California, USA). Dulbecco's Modified Eagle Medium (DMEM) was purchased from EuroClone (Pero, Italy). 4-(2-hydroxyethyl)-1-piperazine-ethanesulfonic acid (HEPES) was obtained from Alfa Aesar (Heysham, England). Fetal bovine serum (FBS) and penicillin-streptomycin solution were obtained from Biowest (California, USA) and Caisson Lab (Rhode Island, USA), respectively. Collagenases II was purchased from Gibco BRL (Maryland, USA). Dimethyl sulfoxide (DMSO) was obtained from Scharlan Chemie S.A. (Barcelona, Spain). Sulfamethoxazole and trimethoprim were kindly provided by Hikma Pharmaceuticals Company (Amman, Jordan), whereas ketoconazole was kindly donated by Dar Al-Dawa Pharmaceuticals Company (Naur, Jordan). 
P450-Glo ${ }^{\text {tw }}$ CYP2C9 with Luciferin-H, P450-Glo ${ }^{\text {tw }}$ 2C8 with Luciferin-ME and P450-Glo ${ }^{\text {ma }}$ 3A4 with Luciferin-IPA Assay kits were purchased from Promega (Madison, USA).

\section{In vivo warfarin-herb interactions}

$\mathrm{CMC}$ at a concentration of $0.5 \%(w / v)$ solution was prepared by dissolving it in water. Concentrations of warfarin solution, guava leaves extract, quercetin, pomegranate peel extract and ellagic acid suspensions were calculated per content concentrations provided by the manufacturers to obtain the needed corresponding doses. Treatments were freshly prepared by dissolving an accurately weighed amount of each material in $0.5 \% \mathrm{CMC}$ solution.

\section{In vivo pharmacodynamic study design}

Adult Sprague Dawley laboratory rats were supplied by the Animal Facility of the University of Petra (Amman, Jordan). Healthy rats were housed under controlled conditions including humidity between 55 to $65 \%$, temperatures between 22 to $24^{\circ} \mathrm{C}$ and photoperiod cycles of $12 \mathrm{~h}$ light/ $12 \mathrm{~h}$ dark in conventional polycarbonate cages of suitable size. Rats were fasted overnight with free access to water. All experiments involving animals were conducted according to the institutional guidelines for the use of laboratory animals, which follows the guidelines of the Federation of European Laboratory Animal Science Associations (FELASA). The used animals were euthanized with cervical dislocation at the end of each experiment. The study protocol was revised and approved by the Committee of Scientific Research of the University of Petra (Approval number: 4-2016/2017, Date: 22/06/2017). The rats were weighed and randomized into ten groups $(n=8)$ and acclimatized for ten days before the experiment. Oral stainless steel gavage needle (Harvard Apparatus, Kent, UK) was used for oral administration of the treatments. Groups were treated daily for five days as following; group 1 received oral $0.5 \% \mathrm{CMC}$ solution and served as a negative control. As for group $2,0.5 \mathrm{mg} / \mathrm{kg}$ warfarin solution was daily administered as a positive control [25]. Group 3 received $100 \mathrm{mg} / \mathrm{kg}$ pomegranate peel extract suspension [26]. While group 4 received warfarin orally in combination with pomegranate peel extract suspension. Group 5 received doses of $40 \mathrm{mg} / \mathrm{kg}$ ellagic acid which represents $40 \%$ of pomegranate peel extract [27, 28], as group 6 received a combination of warfarin and ellagic acid. Group 7 received $250 \mathrm{mg} / \mathrm{kg}$ guava leaves extract suspension [29]. While group 8 received warfarin in combination with guava leaves extract suspension. Finally, groups 9 and 10 , received $12.75 \mathrm{mg} / \mathrm{kg}$ quercetin, which represents $5.1 \%$ of guava leaf extract, and a combination of warfarin and quercetin suspensions, respectively.

\section{Sample collection}

On the fifth day, blood samples were collected from rats and drawn into sodium citrate (3.2\%) micro tubes. The micro tubes were centrifuged at 7000 RPM for $10 \mathrm{~min}$. Plasma was separated, transferred directly into labeled Eppendorf tubes for PT and INR analysis.

\section{Measurement of PT and INR}

Reconstituted thromboplastin was added to $100 \mu \mathrm{l}$ of each plasma sample in pre-warmed cuvette at $37^{\circ} \mathrm{C}$. After $60 \mathrm{~s}, 200 \mu \mathrm{l}$ of starting reagent was added and PT was recorded. INR was calculated from the detected PT according to the manufacturer's instructions.

\section{In vivo pharmacokinetic parallel study design}

Sprague-Dawley rats with an average weight of $220 \pm 10 \mathrm{~g}$ were used to study the effect of natural products (pomegranate peel and guava leaves extracts) in addition to their quality markers (ellagic acid and quercetin) on warfarin pharmacokinetics. Rats were randomized into five groups $(n=8)$ where a control group received a single dose of 0.5 $\mathrm{mg} / \mathrm{kg}$ warfarin solution on the day of experiment. The other four groups received a daily single dose of $250 \mathrm{mg} / \mathrm{kg}$ guava leaves extract, $100 \mathrm{mg} / \mathrm{kg}$ pomegranate peel, 12.75 $\mathrm{mg} / \mathrm{kg}$ quercetin and $40 \mathrm{mg} / \mathrm{kg}$ ellagic acid for five days in combination with a single oral dose of $0.5 \mathrm{mg} / \mathrm{kg}$ warfarin administered on the fifth day [25-29].

\section{Sample collection}

On the fifth day, blood samples were collected from the $18 \mathrm{~h}$ fasted rats at different time intervals namely; at zero time, $0.5,1,2,3,4,6,8,12,24,48$ and $72 \mathrm{~h}$ from all groups and drawn into EDTA micro tubes. The micro tubes were centrifuged at 7000 RPM for $10 \mathrm{~min}$. Plasma was separated, transferred directly into labeled Eppendorf tubes and stored at $-20^{\circ} \mathrm{C}$ until requested for HPLC analysis.

\section{Chromatographic conditions}

Reversed-phase high-performance liquid chromatography (HPLC) analysis was used to separate samples using Finnigan surveyor system (Thermo Electron Corporation, San Jose, California, USA) on a hypersil ${ }^{\mathrm{Tt}}$ BDS C-18 Column $(150 \mathrm{~mm} \times 4.6 \mathrm{~mm}, 5 \mu \mathrm{m})$ (Thermo Electron Corporation, San Jose, California, USA) and quantified using ultraviolet detection at $310 \mathrm{~nm}$ (UV-VIS Plus Detector). The mobile phase was a mixture of $60 \%$ acetonitrile HPLC grade and $40 \%$ water containing $1 \mathrm{ml}$ triethylamine/l and phosphoric acid ( $\mathrm{pH} 3.0$ ) with a flow rate of $1.0 \mathrm{ml} / \mathrm{min}$ (LC pump plus) using $20 \mu \mathrm{l}$ injection volume (Autosampler Plus). Metronidazole benzoate was used as an internal standard. ChromQuest 4.2.34 chromatography data system was implemented for data acquisition and handling. Calibration curve and quality control (QC) samples were prepared by analyzing different concentrations obtained by diluting warfarin stock solution $(400 \mu \mathrm{g} / \mathrm{ml})$ (Fig. 1, Table 1). Consequently, different concentrations of working solutions were prepared for plasma spiking by mixing 


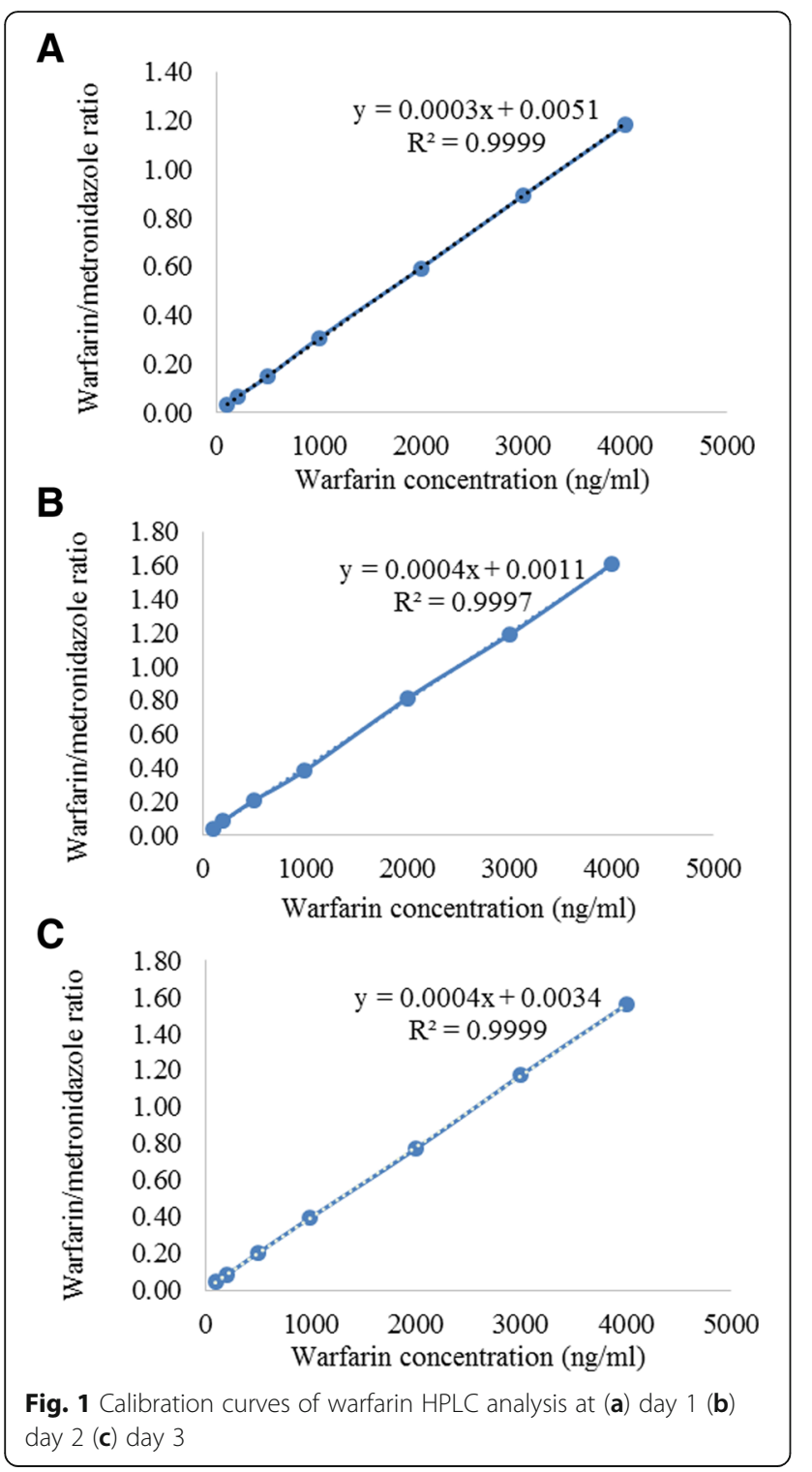

$25 \mu \mathrm{l}$ of working solutions in $975 \mu \mathrm{l}$ of plasma (Fig. 1, Table 1). To extract warfarin from test samples, aliquots of samples $(100 \mu \mathrm{l})$ were mixed with $150 \mu \mathrm{l}$ of acetonitrile containing metronidazole benzoate (I.S., $1.5 \mu \mathrm{g} / \mathrm{ml}$ ) and centrifuged at $14000 \mathrm{RPM}$ for $10 \mathrm{~min}$. The supernatant was then analyzed using an in house validated HPLC method at the Faculty of Pharmacy and Medical Sciences, University of Petra, Amman, Jordan (MSc thesis, Farah Al-Mamoori, 2016, University of Petra). In brief, the analysis method was subjected to full validation where the accuracy, precision, linearity recovery and stability were all calculated and found to be within acceptance criteria of validation guidelines. Inter-day precision and accuracy with CV\% range of $1.22-4.85 \%$ and accuracy range of 97.95-107.76\% were obtained. The coefficient of correlation was 0.9991 with reasonable sensitivity and selectivity.

\section{Pharmacokinetic parameters calculations}

Noncompartmental analysis was used to calculate the detected individual pharmacokinetic parameters for warfarin in the in vivo plasma samples using the Winnonlin program (version 5.2). The calculated pharmacokinetic parameters presented in the current study were maximum plasma concentration $\left(\mathrm{C}_{\max }\right)$, area under the curve (AUC), area under the first moment curve (AUMC), mean residence time (MRT), half-life $\left(t_{0.5}\right)$, clearance $(C L)$, volume of distribution $\left(\mathrm{V}_{\mathrm{z}}\right)$, time at which $\mathrm{C}_{\max }$ was observed $\left(\mathrm{T}_{\max }\right)$ and elimination rate constant $\left(\mathrm{K}_{\mathrm{el}}\right)$.

\section{In vitro cytochrome determinations on primary isolated rat hepatocytes Preparation of buffers}

All perfusion buffers were freshly prepared under sterile conditions and were warmed for $30 \mathrm{~min}$ in a water bath (Elmasonic S, Elma, Germany) at $40^{\circ} \mathrm{C}$. HBSS, without $\mathrm{Ca}^{2+}$ and $\mathrm{Mg}^{2+}$ was used as a perfusion buffer I. Perfusion buffer II was prepared by adding $1000 \mathrm{U}$ of collagenase II

Table 1 Accuracy percentage based on the measured warfarin concentrations of standard points and QC samples. The mean measurements are for day 1, day 2 and day 3

\begin{tabular}{lllll}
\hline $\begin{array}{l}\text { Final calculated } \\
\text { concentration }(\mathrm{ng} / \mathrm{ml})\end{array}$ & $\begin{array}{l}\text { Mean measured } \\
\text { concentration }(\mathrm{ng} / \mathrm{ml})\end{array}$ & Standard Deviation (SD) & \multicolumn{2}{l}{$\begin{array}{l}\text { Coefficient of } \\
\text { Variation }(\% \mathrm{CV})\end{array}$} \\
\hline 100 & 96.84 & 2.19 & 2.27 & 96.84 \\
200 & 201.61 & 9.15 & 4.54 & 100.8 \\
500 & 495.13 & 19.45 & 3.93 & 99.03 \\
1000 & 981.22 & 23.39 & 2.38 & 98.12 \\
2000 & 1969.12 & 53.24 & 2.71 & 98.46 \\
3000 & 2950.57 & 23.15 & 0.78 & 98.35 \\
4000 & 3945.3 & 63.52 & 1.61 & 98.63 \\
QC low (300) & 300.28 & 12.47 & 4.15 & 100.09 \\
QC mid (1800) & 1747.26 & 28.48 & 1.63 & 97.07 \\
QC high (3500) & 3493.65 & 239.92 & 6.87 & 99.82 \\
\hline
\end{tabular}


to HBSS (with $\mathrm{Ca}^{2+}$ and $\mathrm{Mg}^{2+}$ ). This buffer was kept warm in a water-bath and used within $30 \mathrm{~min}$ after preparation. DMEM medium was prepared by the addition of $5 \%$ FBS, $100 \mathrm{IU} / \mathrm{ml}$ penicillin and $100 \mathrm{mg} / \mathrm{ml}$ of streptomycin to DMEM medium.

\section{Liver isolation and incubation}

The liver of anaesthetized rat with inhaled isoflurane were perfused with collagenase enzyme as described by [30]. Liver cells were dispersed gently in a sterile petri dish, and prepared for hepatocyte culture as described elsewhere [31]. Cell were plated at a final concentration of 50,000 cell/100 $\mu \mathrm{l}$ and seeded in 96 well plates $(100 \mu \mathrm{l})$. Cells were left to recover and grow overnight prior to the day of experiment.

\section{Treatment of the cultured cells}

After $16 \mathrm{~h}$ of incubation, each well of cultured rat hepatocytes were treated with $25 \mu \mathrm{l}$ of warfarin, guava leaves extract, quercetin, pomegranate peel extract, ellagic acid, a combination of warfarin with each test compound in addition to the control CYP inhibitors namely; ketoconazole, sulfamethoxazole or trimethoprim. Doses of chemicals selected for in vitro testing on primary cultured hepatocyte mitochondrial activity were estimated after literature review and preliminary work in order to obtain the $\mathrm{IC}_{50}$ values of tested compounds (data not shown). All treatments were dissolved in DMSO then diluted with the DMEM medium to obtain a final concentrations of $3 \mu \mathrm{g} / \mathrm{ml}$ warfarin [32], $294 \mu \mathrm{g} / \mathrm{ml}$ guava leaves extract, $15 \mu \mathrm{g} / \mathrm{ml}$ quercetin [33, 34], $120 \mu \mathrm{g} / \mathrm{ml}$ pomegranate peel extract, $48 \mu \mathrm{g} / \mathrm{ml}$ ellagic acid, $1 \mu \mathrm{g} / \mathrm{ml}$ ketoconazole, $130 \mu \mathrm{g} / \mathrm{ml}$ sulfamethoxazole and $30 \mu \mathrm{g} / \mathrm{ml}$ trimethoprim. Directly after the addition of treatments, $25 \mu \mathrm{l}$ of the lumenogenic substrate (Luciferin- $\mathrm{H}$, Luciferin-ME or Luciferin-IPA) was added to each well. The plates were incubated at $37^{\circ} \mathrm{C}$ for appropriate time according to manufacture protocol (Promega, USA). Later, $25 \mu \mathrm{l}$ from culture media from each well was transferred into 96-well opaque white luminometer plate and equal amount of Luciferin detection reagent was added to each well to initiate the luminescent reaction. The reaction was allowed for $20 \mathrm{~min}$ at room temperature away from light. Finally, luminescence was read using GloMax ${ }^{\circ}$-Multi Detection System (Promega, USA).

\section{Statistical analysis}

Statistical comparisons were made with Independent Student's t-test using SPSS software (version 22). Each data point represents the mean \pm the standard deviation (SD). $P$ value less than 0.05 was considered significant. The statistical analysis of the investigated pharmacokinetic parameters, was performed using ANOVA and Independent Student's t-test after log transformation, except for $\mathrm{T}_{\max }$ where Wilcoxon test was used.
Table 2 Prothrombin time (PT) and International Normalized Ratio (INR) measurements of different rat groups treated with the natural products and their quality markers alone or in combination with warfarin

\begin{tabular}{lll}
\hline Treatment & \multicolumn{2}{l}{ Test } \\
\cline { 2 - 3 } & PT $(\mathrm{s})$ & INR \\
\hline Negative control & $17.3 \pm 0.53$ & $1.0 \pm 0.04$ \\
WF & $191 \pm 12$ & $19 \pm 1^{* *}$ \\
PPE & $21.5 \pm 1.2 \#$ & $1.3 \pm 0.09 \#$ \\
WF + PPE & $360 \pm 36.9^{* *}$ & $42 \pm 5.3^{* *}$ \\
EA & $23 \pm 1.31 \#$ & $1.43 \pm 0.10 \#$ \\
WF + EA & $414 \pm 139^{* *}$ & $51 \pm 19^{* *}$ \\
GVL & $23.3 \pm 1.04 \#$ & $1.44 \pm 0.08 \#$ \\
WF + GVL & $425 \pm 57^{* *}$ & $52 \pm 8.4^{* *}$ \\
QUE & $22.5 \pm 1.20 \#$ & $1.39 \pm 0.09 \#$ \\
WF + QUE & $448 \pm 79^{* *}$ & $55 \pm 11^{* *}$ \\
\hline
\end{tabular}

Each data point represents the mean \pm SD $(n=8)$. ${ }^{* *} p<0.01$ (in comparison with warfarin alone). \# $p<0.01$ (in comparison with the negative control)

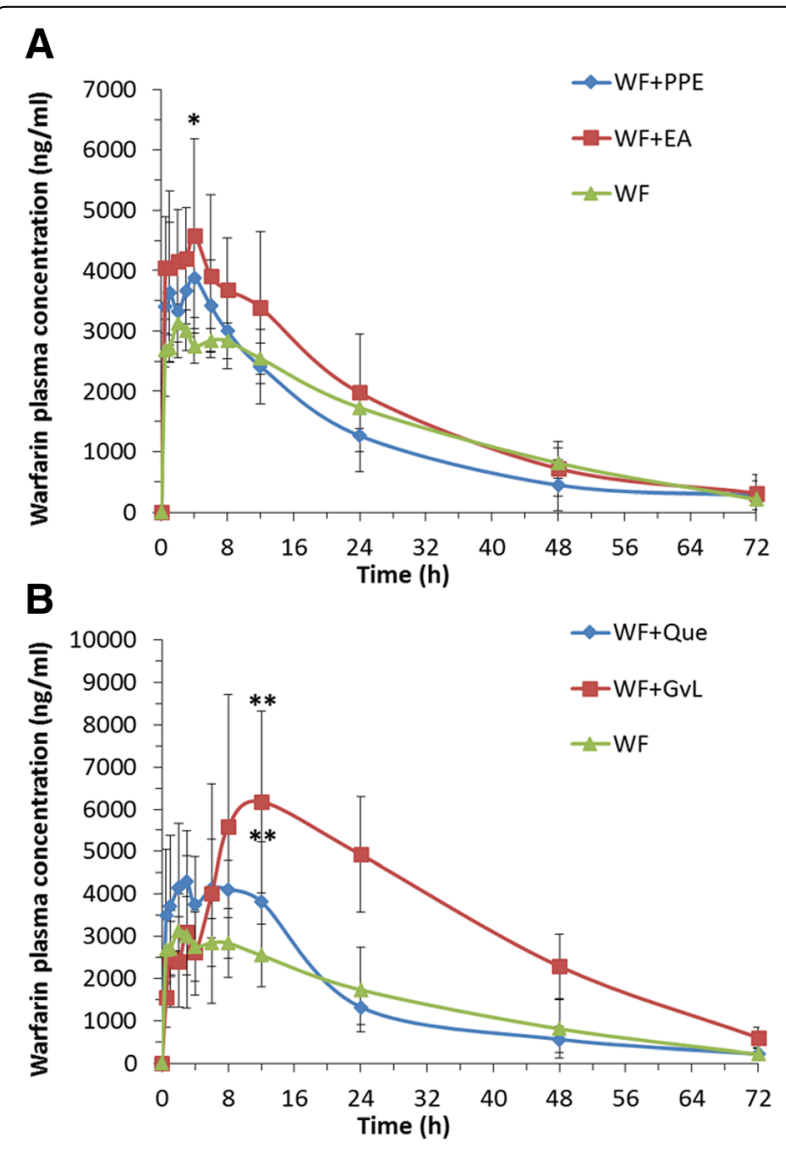

Fig. 2 In vivo plasma concentrations of warfarin versus time curves in rats after a single oral dose of $0.5 \mathrm{mg} / \mathrm{kg}$ warfarin, along with warfarin in combination with: (a) five doses of pomegranate peel extract (100 mg/kg) and ellagic acid (40 mg/kg), (b) five doses of guava leaves extract $(250 \mathrm{mg} / \mathrm{kg})$ and quercetin $(12.75 \mathrm{mg} / \mathrm{kg})$. Each data point represents the mean $\pm \operatorname{SEM}(n=8) .{ }^{*} p<0.05,{ }^{* *} p<0.01$ 


\section{Results}

\section{In vivo pharmacodynamics results}

As illustrated in Table 2, both pomegranate peel and guava leaf extracts and their quality markers, ellagic acid and quercetin significantly increased PT and INR values upon concomitant administration with warfarin $(p<0.01)$. In addition, mentioned extracts and chemicals presented increase in PT and INR values when compared to control group $(p<0.05)$.

\section{In vivo pharmacokinetics results}

Pomegranate peel extract showed insignificant effects on warfarin pharmacokinetics $(p>0.05)$. Nonetheless, ellagic acid significantly increased warfarin $C_{\max }(p<0.05)$ (Fig. 2a). As for pharmacokinetic interaction of warfarin with guava leaves extract and quercetin, the results showed that both treatments significantly increased warfarin $C_{\max }$ when compared to control $(p<0.01)$ (Fig. 2b). Furthermore, guava leaves extract showed a significant effect on changing the AUC, CL and $\mathrm{V}_{\mathrm{z}}$ (Table 3).

\section{In vitro cytochrome interactions}

All utilized control inhibitors namely; sulfamethoxazole, trimethoprim and ketoconazole significantly reduced corresponding CYPs, CYP2C9, 2C8 and 3A4 activities, respectively $(p<0.01)$ (Figs. 3, 4 and 5). Activities of CYP2C9, 2C8 and 3A4 in primary cultured hepatocytes were not affected by warfarin (Figs. 3, 4 and 5). On the other hand, results indicated that pomegranate peel, whether used alone or in combination with warfarin, did not have any significant effect on all three CYPs (Figs. 3a, 4a and 5a). Combination of ellagic acid with warfarin significantly inhibited activities of CYP2C8,
$2 \mathrm{C} 9$ and 3A4 $(p<0.05)$, however treatment of cells with ellagic acid alone presented significant inhibition on CYP2C9 activity despite other CYPs $(p<0.05)$ (Figs. 3a, 4a and 5a).

Although guava leaves extract showed an insignificant effect on CYP2C8 when used alone, it significantly reduced its activity when combined with warfarin $(p<0.01)$ (Fig. 4b) and however, inhibited the activities of CYP2C9 and 3A4 when used alone and concomitantly with warfarin ( $p$-values are marked in Figs. $3 \mathrm{~b}$ and $5 \mathrm{~b})$. Furthermore, quercetin inhibited activities of all three CYPs whether administered alone or concomitantly with warfarin ( $p$-values are marked in Figs. 3b, $4 \mathrm{~b}$ and $5 \mathrm{~b}$ ).

\section{Discussion}

Significant drug-herb interactions were found between warfarin and the tested herbs. Pharmacodynamic results support a previous study reported by Sampath et al. (2016) which showed that pomegranate peel extract had in vitro thrombolytic activity when added to clots formed from human blood samples [13]. Besides, it was demonstrated that ellagitannins in pomegranate peel in addition to ellagic acid possessed strong action in reducing platelet aggregation when incubated with washed human platelet-rich plasma samples [14]. It was also reported that ellagic acid significantly inhibited human platelet aggregation against aggregation inducer in in vitro model [35]. Therefore, the increase in PT values post treating rats with pomegranate peel extract might be explained by the additive antiplatelet activity exerted by the extract. The impact of guava leaves and its quality marker, quercetin, on PT and INR values might be

Table 3 Pharmacokinetic parameters (PK) of warfarin alone $(0.5 \mathrm{mg} / \mathrm{kg})$ or in combination with the investigated natural products and their quality markers

\begin{tabular}{|c|c|c|c|c|c|}
\hline \multirow[t]{2}{*}{ PK Parameter } & \multicolumn{5}{|l|}{ Treatment } \\
\hline & WF $(0.5 \mathrm{mg} / \mathrm{kg})$ & WF \& PPE (100 mg/kg) & WF \& EA (40 mg/kg) & WF \& GVL (250 mg/kg) & WF \& Que. (12.75 mg/kg) \\
\hline$C_{\max }(\mathrm{ng} / \mathrm{ml})$ & $3670 \pm 663$ & $4218 \pm 843$ & $4981 \pm 1363^{*}$ & $6962 \pm 2358^{* *}$ & $5428 \pm 1110^{* *}$ \\
\hline $\mathrm{T}_{\max }(\mathrm{h})$ & $6 \pm 8$ & $3 \pm 1.58$ & $3 \pm 1.58$ & $11 \pm 6$ & $5 \pm 4$ \\
\hline AUC.inf $\left(h^{*} n g / m l\right)$ & $106,613 \pm 30,987$ & $99,457 \pm 43,116$ & $131,661 \pm 57,014$ & $252,566 \pm 51899^{* *}$ & $115,904 \pm 24,544$ \\
\hline $\mathrm{K}_{\mathrm{el}}(\mathrm{ml} / \mathrm{h})$ & $0.044 \pm 0.01$ & $0.035 \pm 0.008$ & $0.046 \pm 0.01$ & $0.044 \pm 0.01$ & $0.039 \pm 0.006$ \\
\hline $\mathrm{t}_{0.5}(\mathrm{~h})$ & $17 \pm 4$ & $21 \pm 5$ & $16 \pm 4.6$ & $17 \pm 5$ & $18 \pm 3$ \\
\hline MRT (h) & $25 \pm 5$ & $25 \pm 7.7$ & $23 \pm 6.5$ & $30 \pm 6$ & $22 \pm 6$ \\
\hline $\mathrm{CL} / \mathrm{F}(\mathrm{ml} / \mathrm{h})$ & $1.45 \pm 0.5$ & $1.54 \pm 0.5$ & $1.17 \pm 0.4$ & $0.61 \pm 0.17^{* *}$ & $1.14 \pm 0.32$ \\
\hline $\mathrm{V}_{\mathrm{z}} / \mathrm{F}(\mathrm{ml})$ & $35 \pm 15$ & $45 \pm 11.4$ & $26 \pm 6.8$ & $15 \pm 5^{* *}$ & $30 \pm 8$ \\
\hline AUMC-inf.(h*h*ng/m) & $2,760,227 \pm 1,140,965$ & $2,762,909 \pm 2,177,721$ & $3,363,635 \pm 2,416,054$ & $7,630,361 \pm 1894405^{* *}$ & $2,594,574 \pm 1,058,762$ \\
\hline \%Change in $\mathrm{C}_{\max }$ & - & 15 & $36^{*}$ & $90^{* *}$ & $48^{* *}$ \\
\hline \%Change in AUC.inf & - & -7 & 23 & $137^{* *}$ & 9 \\
\hline \%Change in $\mathrm{CL}$ & - & 6 & -19 & $-58^{* *}$ & -21 \\
\hline$\%$ Change in $V_{z}$ & - & 29 & -26 & $-57^{* *}$ & -14 \\
\hline
\end{tabular}

The data are presented as mean \pm SD $(n=8) .{ }^{*} p<0.05,{ }^{*} p<0.01$ 

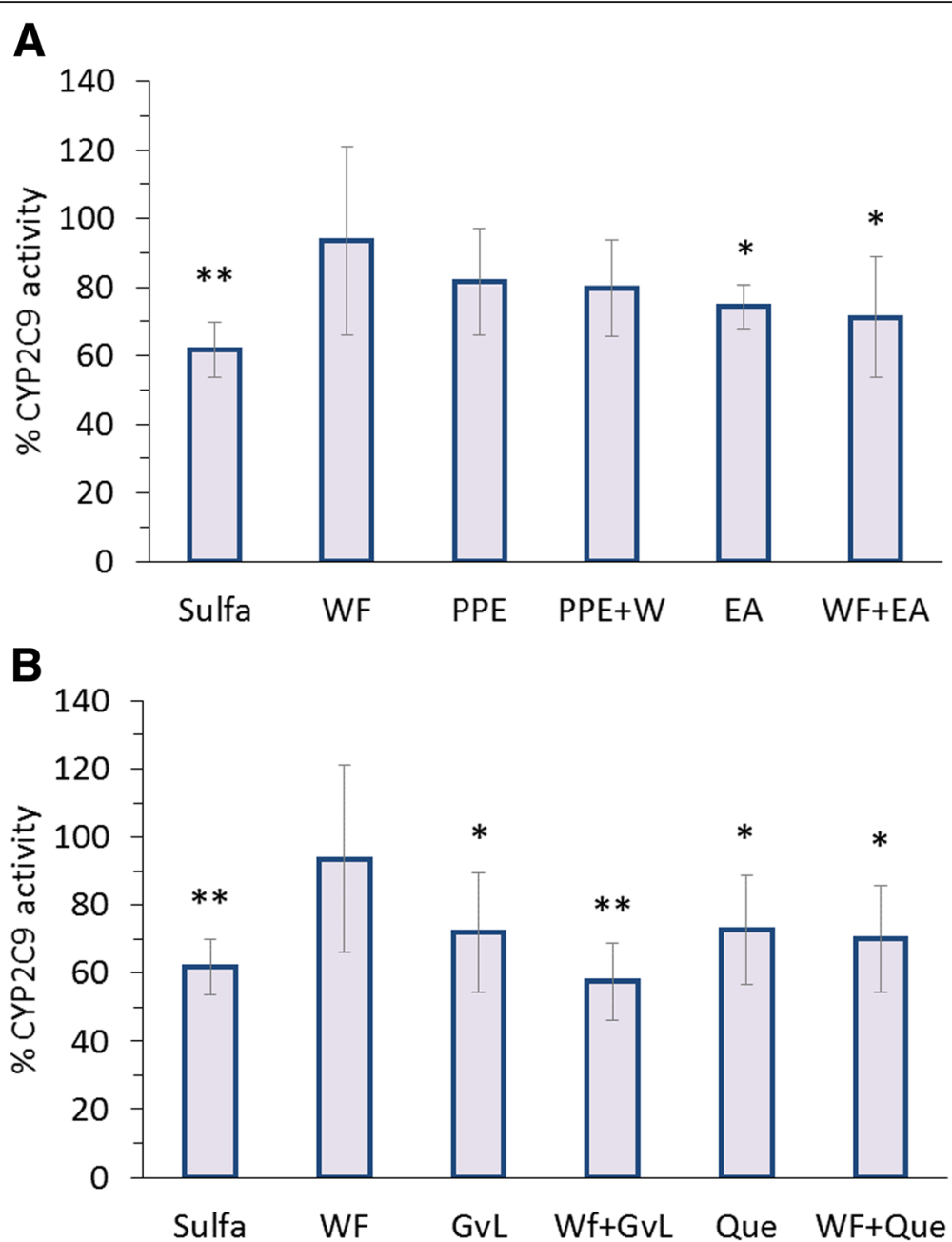

Fig. 3 Percentage of CYP2C9 activity relative to untreated isolated hepatocytes of different groups treated with sulfamethoxazole $(130 \mu \mathrm{g} / \mathrm{ml})$ and warfarin $(3 \mu \mathrm{g} / \mathrm{ml})$ alone or in combination with: (a) pomegranate peel extract $(120 \mu \mathrm{g} / \mathrm{ml})$, ellagic acid $(48 \mu \mathrm{g} / \mathrm{ml})$ or, (b) guava leaves extract $(294.1 \mu \mathrm{g} / \mathrm{ml})$ and quercetin $(15 \mu \mathrm{g} / \mathrm{ml})$. Each data point represents the mean \pm SD $(n=6)$. Statistical evaluation was performed by comparing the percentage of activity of untreated cells with treated cells ${ }^{*} p<0.05,{ }^{* *} p<0.01$

also attributed to the antiplatelet activity of flavonoids which are constituents of guava leaves extract, especially quercetin, which may potentially increase the risk of bleeding or potentiate the effects of warfarin therapy as previously reported [23]. An in vitro study showed that guava leaves extract along with some of its active constituents such as quercetin, gallic acid and ferulic acid had anticoagulant activity by preventing methylglyoxal-induced loss of activity of antithrombin III, thus, reduced glycation-associated hypercoagulable state that accelerate thrombosis formation [24]. No previous studies reported the effect of guava leaves extract and quercetin on the pharmacodynamics of warfarin. Therefore, the current investigation highlighted the presence of substantial interaction between warfarin and guava leaves and quercetin.

The investigated pharmacokinetic interactions of warfarin with pomegranate peel extract and ellagic acid confirmed that no significant effect was found in pomegranate peel extract on warfarin plasma concentration despite the increase in warfarin $\mathrm{C}_{\max }$ upon ellagic acid administration. This could be explained by the low content of ellagitannins in pomegranate peel which consist of ellagic acid as a building block due to their large molecular size, poor lipid solubility and metabolism by intestinal flora [36, 37]. Noteworthy, the evaluation of CYP450 enzymes, namely, CYP2C9, 2C8, 3A4 was based on cell-based investigations and sufficient inhibition of corresponding well-known CYP control inhibitors including, sulfamethoxazole, trimethoprim and ketoconazole confirms that in vitro investigation of mentioned CYP isoforms on rat hepatocyte is possible, as raised in the literature $[38,39]$. In regard to results presented for ellagic acid, and since it is known to exert inhibition on CYP2C9, its effect may be due to a decrease 

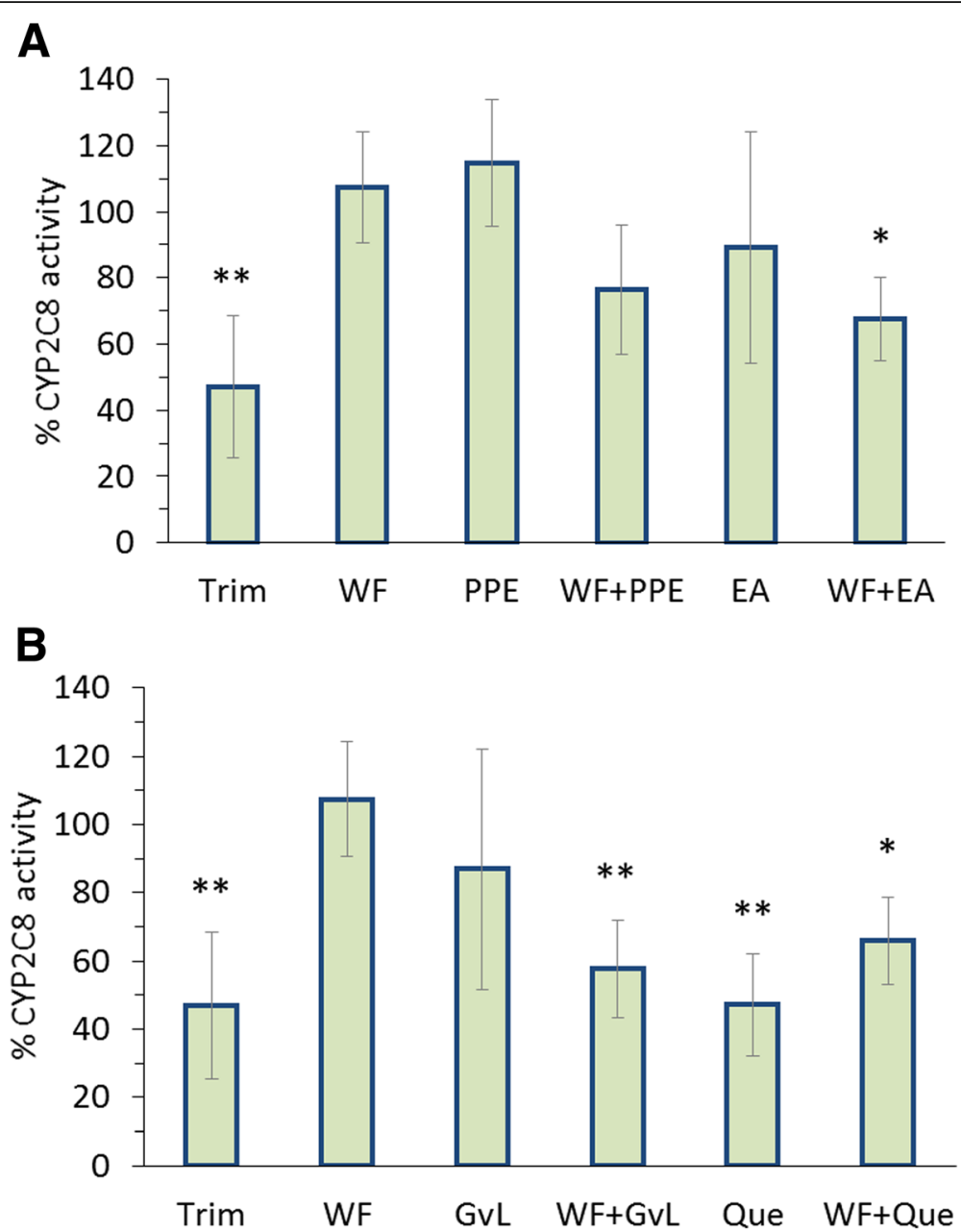

Fig. 4 Percentage of CYP2C8 activity relative to untreated isolated hepatocytes of different groups treated with trimethoprim ( $30 \mu \mathrm{g} / \mathrm{ml})$, and warfarin $(3 \mu \mathrm{g} / \mathrm{ml})$ alone or in combination with: (a) pomegranate peel extract $(120 \mu \mathrm{g} / \mathrm{ml})$, ellagic acid $(48 \mu \mathrm{g} / \mathrm{ml})$ or, (b) guava leaves extract $(294.1 \mu \mathrm{g} / \mathrm{ml})$ and quercetin $(15 \mu \mathrm{g} / \mathrm{ml})$. Each data point represents the mean \pm SD $(n=6)$. Statistical evaluation was performed by comparing the percentage of activity of untreated cells with treated cells ${ }^{*} p<0.05,{ }^{* *} p<0.01$

in hepatic first-pass metabolism of warfarin due to its ability to inhibit such CYP isoform (Fig. 3a) [40]. Recently, it has been confirmed that ellagic acid can significantly inhibit CYP3A and P-glycoprotein (P-gp)-mediated efflux in the intestine [41], thus, increase warfarin plasma concentration and its pharmacological effect.

As for the pharmacokinetic interaction of warfarin with guava leaves extract and quercetin, and the effect both exerted on increasing warfarin $C_{\max }$, the interaction is possibly accounted to different reasons including; the availability of flavonoids in guava leaves, including quercetin, which had a very strong affinity for the same primary binding site of warfarin on serum albumin. Consequently, their simultaneous uptake may cause a competitive inhibition by displacing warfarin, leading to an increase in its free form, that would increase warfarin plasma concentration $[22,36]$. Another reason can be attributed to quercetin which exerts absorption enhancement activity by inhibiting the intestinal efflux pumps [42]. Absorption enhancement might cause increase in the warfarin's plasma $\mathrm{C}_{\max }$ and AUC. Furthermore, the ability of guava leaves extract and quercetin to inhibit some of hepatic CYP isoforms associated with warfarin metabolism such as CYP2C9, 2C8 and 3A4 may be responsible for increasing warfarin plasma concentration [40,43]. No previous studies have reported the pharmacokinetics of warfarin in presence of guava leaves extract, pomegranate peel extract, quercetin or ellagic acid.

In vitro warfarin-herb interactions and their effects on hepatic CYP isoforms showed that CYP2C9, $2 \mathrm{C} 8$ and $3 \mathrm{~A} 4$ activities in primary isolated and cultured rat hepatocytes were not affected by warfarin (Figs. 3a, 4a and 5a).

Pomegranate peel, did not have any significant effect on the three CYPs in rat hepatocytes whether used alone or in combination with warfarin (Figs. 3a, 4a and 5a). 


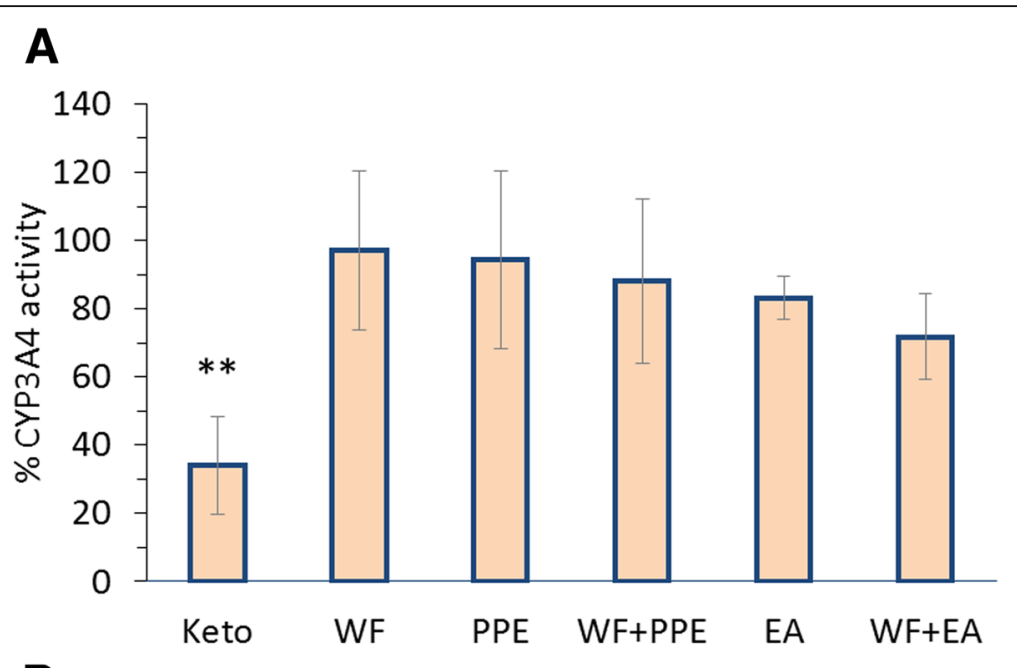

B

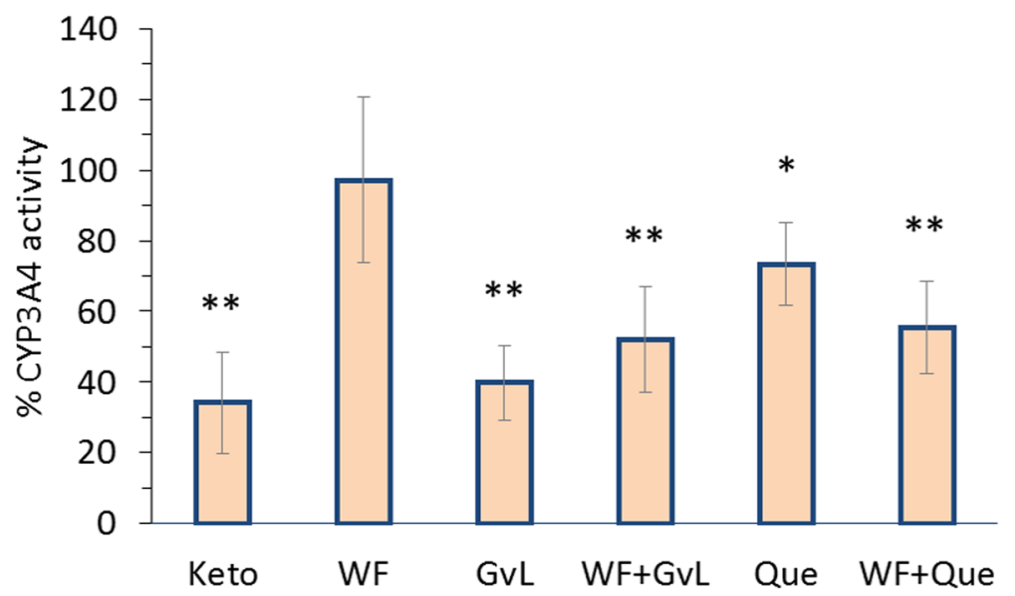

Fig. 5 Percentage of CYP3A4 activity relative to untreated isolated hepatocytes of different groups treated with ketoconazole $(1 \mu \mathrm{g} / \mathrm{ml})$ and warfarin $(3 \mu \mathrm{g} / \mathrm{ml})$ alone or in combination with: (a) pomegranate peel extract $(120 \mu \mathrm{g} / \mathrm{ml})$, ellagic acid $(48 \mu \mathrm{g} / \mathrm{ml})$ or, (b) guava leaves extract $(294.1 \mu \mathrm{g} / \mathrm{ml})$ and quercetin $(15 \mu \mathrm{g} / \mathrm{ml})$. Each data point represents the mean \pm SD $(n=6)$. Statistical evaluation was performed by comparing the percentage of activity of untreated cells with treated cells ${ }^{*} p<0.05,{ }^{* *} p<0.01$

Since CYP isoforms other than $2 \mathrm{C} 9,2 \mathrm{C} 8$ and $3 \mathrm{~A} 4$ are involved in warfarin metabolism, further study with more focus on pomegranate peel and its constituents is therefore suggested.

Significant reduction exerted by the use of ellagic acid whether used alone or concomitantly with warfarin is in line with those reported in previous studies [40] which showed that ellagic acid had inhibitory effect on many CYPs isoforms including CYP2C9. It is generally known that CYPs often possess enzyme specific catalytic repertoires and can display exquisite catalytic selectivity for regio- and stereo-specific reactions [44]. The mammalian isoforms have been reported to attain some degree of flexibility in its structure, including what is called peripheral binding sites that can influence substrate binding and oxidation. Therefore, it can be suggested that ellagic acid may affect warfarin binding to
CYP2C8 and CYP3A4 by changing the conformation of these enzymes that leads to more affinity towards warfarin binding $[45,46]$. These results contradict those of a previous study by Kaneko, 2013 where ellagic acid had a clear inhibitory effect on CYP2C8 and CYP3A4 activities [40]. In reviewing the literature, no data was found on warfarin combinations with pomegranate peel extract and ellagic acid effect on CYP2C9, 2C8 and 3A4 activities.

The observed reduction in CYP2C9 activity upon treatment with by guava leaves extract, quercetin and their combinations with warfarin could be attributed to the competitive inhibitory effect of quercetin on CYP2C9 [37]. These results were consistent with previous studies that demonstrated the inhibitory effects of guava leaves extract and quercetin on CYP2C9 activity [40, 43]. 
Although guava leaves extract showed an insignificant effect on CYP2C8 when used alone, it significantly reduced its activity when combined with warfarin $(p<0.01)$ (Fig. 4b). In a previous study conducted by Kaneko in 2013, it was reported that guava leaves extract had an inhibitory effect on CYP2C8 [40]. Therefore, it might be suggested that CYP2C8 enzyme can be influenced by the presence of warfarin, which can modify the uncompetitive binding of the active extract components on the enzyme. It seems possible that some competition could have happened between quercetin and warfarin on the binding site of $\mathrm{CYP} 2 \mathrm{C} 8$ since previous studies showed that quercetin can competitively inhibit the effect of CYP2C8 [40,47]. Thus, explains the influence of quercetin in reducing CYP2C8 activity in tested rat hepatocytes.

It has been suggested that guava leaves extract constituents, such as gallic acid and ursolic acid, have the ability to diminish the activity of CYP3A4 in human liver microsomes $[37,48]$. That comes in line with the results obtained from testing guava leaves extract both alone and in combination with warfarin in significantly affecting CYP3A4 activity in primary isolated rat hepatocytes. Further reduction in CYP3A4 activity was observed upon administerating quercetin concomitantly with warfarin, suggesting that CYP3A4 may undergo an allosteric change during its binding with warfarin that possibly enhances quercetin binding which leads to increase its inhibitory effect [49]. Such assumption needs further investigation.

Finally, it was clear that guava leaves extract, quercetin and ellagic acid showed pharmacodynamic and pharmacokinetic interactions with warfarin. The possible mechanism for that is their inhibitory effect on CYP2C9, 2C8 and 3A4 isoforms which are responsible for warfarin metabolism. Conversely, pomegranate peel extract only showed pharmacodynamic interaction when combined with warfarin as it did not affect pharmacokinetic parameters or CYPs activity. It seems other mechanisms involved in the demonstrated pharmacodynamic interaction of pomegranate peel extract.

\section{Conclusion}

All studied combinations enhanced the anticoagulant effect of warfarin. The interaction between warfarin and pomegranate peel was mainly pharmacodynamic. On the other hand, ellagic acid, guava leaves and quercetin exhibited both pharmacodynamic and pharmacokinetic interactions. The previously mentioned interactions might be attributed to the inhibitory effects of guava leaves, quercetin and ellagic acid on CYP2C9, 2C8 and 3A4 that are responsible for the metabolism of warfarin.

The current investigation suggests a high risk of bleeding that may arise from the co-administration of pomegranate peel and guava leaves extracts with warfarin therapy. It should always be considered that other active components might be present in the tested plants in addition to the presence of other isoforms of CYPs involved in warfarin's metabolism and all these components is suggested to be investigated in the future. Currently however, awareness on the reported interactions is essential to be spread among the healthcare practitioners and should be taken it into consideration in order to minimize any unnecessary interactions between warfarin and the reported herbal constituents.

\section{Abbreviations \\ AUC: Area under curve; AUMC: Area under moment curve; Ca: Calcium; CL: Clearance; Cmax: Maximum plasma concentration; CMC: Carboxy Methyl Cellulose; CV: Coefficient of Variation; CYP: Cytochrome; DMEM: Dulbecco's Modified Eagle Medium; DMSO: Dimethyl Sulfoxide; EA: Ellagic acid; EDTA: Ethylene Diamine Tetra Acetic Acid; EMEA: European Medicines Agency; FELASA: Federation European of Laboratory Animal Sciences Association; GVL: Guava leaves Extract; HBSS: Hank's Balanced Salt Solution; HEPES: (4-(2-hydroxyethyl)-1-piperazineethanesulfonic acid); HPLC: High Performance Liquid Chromatography; HPV: Hepatic Portal Vein; INR: International Normalized Ratio; IS: Internal Standard; ISI: International Sensitivity Index; IVC: Inferior Vena Cava; Kel: Elimination rate Constance; Mg: Magnesium; MRT: Mean Residence Time; PK: Pharmacokinetic; PPE: Pomegranate Peel Extract; PT: Prothrombin Time; QC: Quality Control; Que.: Quercetin; R2: Regression; RPM: Rotation Per Minutes; SD: Standard Deviation; SEM: Standard Error of Mean; t0.5: Half Life; Tmax: The time in which maximum plasma concentration is reached; Vz: Volume of Distribution; WF: Warfarin}

\section{Acknowledgements}

The authors would like to thank the Deanship of Scientific Research, University of Petra for funding the project.

\section{Funding}

The Deanship of Scientific Research at the University of Petra, Amman, Jordan, funded the presented research. Funding numbers 3/4/2016, 4/7/2014 and $9 / 4 / 2017$

\section{Availability of data and materials}

The datasets used and/or analyzed during the current study are available from the corresponding author on reasonable request.

\section{Authors' contributions}

$\mathrm{MA}, \mathrm{KM}, \mathrm{EM}, \mathrm{BG}$ and $\mathrm{NQ}$ conducted the research. NQ and NI analyzed data and critically read the article. All authors read and approved the final manuscript.

\section{Ethics approval and consent to participate}

All animal experiments were performed in accordance with the University of Petra Institutional Guidelines on Animal Use which adopts the guidelines of the Federation of European Laboratory Animal Science Association. The study protocol was revised and approved by the Committee of Scientific Research of the University of Petra (Approval number: 4-2016/2017, Date: 22/06/2017)

\section{Consent for publication}

Not applicable.

\section{Competing interests}

The authors declare that they have no competing interests.

\section{Publisher's Note}

Springer Nature remains neutral with regard to jurisdictional claims in published maps and institutional affiliations. 


\section{Author details}

'Department of Pharmacology and Biomedical Sciences, Faculty of Pharmacy and Medical Sciences, University of Petra, Airport Road, P.O. Box 961343, Amman, Jordan. ${ }^{2}$ Department of Pharmaceutical Medicinal Chemistry and Pharmacognosy, Faculty of Pharmacy and Medical Sciences, University of Petra, Amman, Jordan. ${ }^{3}$ University of Petra Pharmaceutical Center (UPPC), University of Petra, Amman, Jordan.

\section{Received: 28 June 2018 Accepted: 14 January 2019}

Published online: 24 January 2019

\section{References}

1. Rahimi S, Zadeh ZT, Torshizi MAK, Omidbaigi R, Rokin H. Effect of the three herbal extracts on growth performance, immune system, blood factors and intestinal selected bacterial population in broiler chickens S. J Agric Sci Technol. 2011;13:527-39.

2. Jiang X, Williams KM, Liauw WS, Ammit AJ, Roufogalis BD, Colin. Effect of St John's wort and ginseng on the pharmacokinetics and pharmacodynamics of warfarin in healthy subjects. Br J Clin. 2004;57:592-9. https://doi.org/10. 1111/j.1365-2125.2004.02051.x.

3. Wang L, Hai Y, Huang N, Gao X, Liu W, He X. Human cytochrome P450 enzyme inhibition profile of three flavonoids isolated from: Psoralea corylifolia: in silico predictions and experimental validation. New J Chem. 2018;42:10922-34. https://doi.org/10.1039/c7nj00884h.

4. Krrižková J, Burdová K, Stiborová M, Křen V, Hodek P. The effects of selected flavonoids on cytochromes P450 in rat liver and small intestine. Interdiscip Toxicol. 2009;2:201-4. https://doi.org/10.2478/v10102-009-0018-y.

5. Celik G, Semiz A, Karakurt S, Arslan S, Adali O, Sen A. A comparative study for the evaluation of two doses of ellagic acid on hepatic drug metabolizing and antioxidant enzymes in the rat. Biomed Res Int. 2013; 2013:358945. https://doi.org/10.1155/2013/358945.

6. Vijayakumar TM, Kumar RM, Agrawal A, Dubey GP, llango K. Comparative inhibitory potential of selected dietary bioactive polyphenols, phytosterols on CYP3A4 and CYP2D6 with fluorometric high-throughput screening. J Food Sci Technol. 2014:52:4537-43.

7. Qnais EY, Elokda AS, Ghalyun YYA, Abdulla FA. Antidiarrheal activity of the aqueous extract of Punica granatum (pomegranate) peels. Pharm Biol. 2007; 45:715-20.

8. Voravuthikunchai SP, Mitchell H. Inhibitory and killing activities of medicinal plants against multiple antibiotic-resistant helicobacter pylori. J Heal Sci. 2008:54:81-8.

9. Kanatt SR, Chander R, Sharma A. Antioxidant and antimicrobial activity of pomegranate peel extract improves the shelf life of chicken products. Int $J$ Food Sci Technol. 2010;45:216-22.

10. Neyrinck AM, Van Hée VF, Bindels LB, De Backer F, Cani PD, Delzenne NM. Polyphenol-rich extract of pomegranate peel alleviates tissue inflammation and hypercholesterolaemia in high-fat diet-induced obese mice: potential implication of the gut microbiota. Br J Nutr. 2013;109:802-9.

11. Nawwar MAM, Hussein SAM, Merfort I. NMR spectral analysis of polyphenols from Punica granatum. Phytochemistry. 1994:36:793-8.

12. Riaz A, Khan RA. Anticoagulant, antiplatelet and antianemic effects of Punica granatum (pomegranate) juice in rabbits. Blood Coagul Fibrinolysis. 2016;27: 287-93. https://doi.org/10.1097/MBC.0000000000000415.

13. Sampath $R$, Saravanan $R$, Pemiah B, Ramalingam $S$. Thrombolytic activity of Punica granatum fruit and peel extract. Asian J Pharm Clin Res. 2016:9:250-3.

14. Mattiello T, Trifirò E, Jotti GS, Pulcinelli FM. Effects of pomegranate juice and extract polyphenols on platelet function. J Med Food. 2009;12:334-9. https://doi.org/10.1089/jmf.2007.0640.

15. Chang Y, Chen W-F, Lin K-H, Hsieh C-Y, Chou D-S, Lin L-J, et al. Novel bioactivity of Ellagic acid in inhibiting human platelet activation. Evid Based Complement Alternat Med. 2013;2013. https://doi.org/10.1155/2013/595128.

16. Elwej A, Ben Salah G, Kallel C, Fakhfakh F, Zeghal N, Ben Al. Protective effects of pomegranate peel against hematotoxicity, chromosomal aberrations, and genotoxicity induced by barium chloride in adult rats. Pharm Biol. 2016:54:964-74. https://doi.org/10.3109/13880209.2015.1087035.

17. Jaiarj $P$, Khoohaswan $P$, Wongkrajang $Y$, Peungvicha $P$, Suriyawong $P$, Sumal Saraya ML, et al. Anticough and antimicrobial activities of Psidium guajava Linn. Leaf extract. J Ethnopharmacol. 1999:67:203-12.

18. Belemtougri RG, Constantin B, Cognard C, Raymond G, Sawadogo L. Effects of two medicinal plants Psidium guajava L. (Myrtaceae) and Diospyros mespiliformis L. (Ebenaceae) leaf extracts on rat skeletal muscle cells in primary culture. J Zhejiang Univ Sci B. 2006;7:56-63. https://doi.org/10.1631/ jzus.2006.B0056.

19. Deguchi Y, Miyazaki K. Anti-hyperglycemic and anti-hyperlipidemic effects of guava leaf extract. Nutr Metab (Lond). 2010;7:9. https://doi.org/10.1186/ 1743-7075-7-9.

20. Metwally AM, Omar AA, Ghazy NM, Harraz FM, El Sohafy SM. Monograph of Psidium guajava L. leaves. Pharmacogn J. 2011;3:89-104. https://doi.org/10. 5530/pj.2011.21.17.

21. Marc Gregory L. Omega, Maria Catherine A. Quiapo, Carlos N. Quizon III, Annah S. Teves. Anticoagulant activity of Psidium guajava (guava) leaves methanol extract in ICR mice. University of the Visayas; 2017. http://www. herdin.ph/index.php/component/herdin/?view=research\&cid=63372. Accessed 28 Oct 2018

22. Poór M, Boda G, Needs PW, Kroon PA, Lemli B, Bencsik T. Interaction of quercetin and its metabolites with warfarin: displacement of warfarin from serum albumin and inhibition of CYP2C9 enzyme. Biomed Pharmacother. 2017:88:574-81. https://doi.org/10.1016/j.biopha.2017.01.092.

23. Mozzicafreddo M, Cuccioloni M, Eleuteri AM, Fioretti E, Angeletti M. Flavonoids inhibit the amidolytic activity of human thrombin. Biochimie. 2006;88:1297-306

24. Hsieh CL, Lin YC, Yen GC, Chen HY. Preventive effects of guava (Psidium guajava L.) leaves and its active compounds against a-dicarbonyl compounds-induced blood coagulation. Food Chem. 2007;103:528-35.

25. Guo C, Xue S, Zheng X, Lu Y, Zhao D, Chen X, et al. The effect of fenofibric acid on the pharmacokinetics and pharmacodynamics of warfarin in rats. Xenobiotica. 2018;48:400-6. https://doi.org/10.1080/00498254.2017.1306760.

26. Moghaddam G, Sharifzadeh M, Hassanzadeh G, Khanavi M, Hajimahmoodi M. Anti-Ulcerogenic activity of the pomegranate Peel (Punica granatum) methanol extract. Food Nutr Sci. 2013;04:43-8. https://doi.org/10.4236/fns.2013.410A008.

27. Lansky EP. Beware of pomegranates bearing 40\% ellagic acid. J Med Food. 2006;9:119-22. https://doi.org/10.1089/jmf.2006.9.119.

28. Saha P, Yeoh BS, Singh R, Chandrasekar B, Vemula PK, Haribabu B, et al. Gut microbiota conversion of dietary ellagic acid into bioactive phytoceutical urolithin a inhibits heme peroxidases. PLoS One. 2016;11:e0156811. https:// doi.org/10.1371/journal.pone.0156811.

29. Mukhtar $\mathrm{H}$, Ansari S, Ali M, Naved T, Bhat Z. Effect of water extract of Psidium guajava leaves on alloxan-induced diabetic rats. Pharmazie. 2004;59:734-5.

30. Al Shaker HA, Qinna NA, Badr M, Al Omari MMH, Idkaidek N, Matalka KZ, et al. Glucosamine modulates propranolol pharmacokinetics via intestinal permeability in rats. Eur J Pharm Sci. 2017;105:137-43. https://doi.org/10. 1016/j.ejps.2017.05.012

31. Shen L, Hillebrand A, Wang DQ-H, Liu M. Isolation and Primary Culture of Rat Hepatic Cells. J Vis Exp. 2012:2-5. https://doi.org/10.3791/3917.

32. Beazley KE, Eghtesad S, Nurminskaya MV. Quercetin attenuates warfarininduced vascular calcification in vitro independently from matrix gla protein. J Biol Chem. 2013;288:2632-40. https://doi.org/10.1074/jbc.M112.368639.

33. Pawlikowska-Pawlęga B, Dziubińska H, Król E, Trębacz K, Jarosz-Wilkołazka A Paduch $\mathrm{R}$, et al. Characteristics of quercetin interactions with liposomal and vacuolar membranes. Biochim Biophys Acta - Biomembr. 2014;1838 1 PARTB:254-65. https://doi.org/10.1016/j.bbamem.2013.08.014.

34. Conklin CMJ, Bechberger JF, MacFabe D, Guthrie N, Kurowska EM, Naus CC. Genistein and quercetin increase connexin43 and suppress growth of breast cancer cells. Carcinogenesis. 2007;28:93-100. https:/doi.org/10.1093/carcin/bgl106.

35. Moschona A, Kyriakidis KD, Kleontas AD, Liakopoulou- M. Comparative Study of Natural Phenolic Acids and Flavonols as Antiplatelet and AntiInflammatory Agents. Grant Med Journals. 2017;02:57-66.

36. Di Bari L, Ripoli S, Pradhan S, Salvadori P. Interactions between quercetin and Warfarin for albumin binding: A new eye on food/drug interference. Chirality. 2010;22(6):593-6. https://doi.org/10.1002/chir.20794.

37. Espín JC, González-Barrio R, Cerdá B, López-Bote C, Rey Al, Tomás-Barberán FA Iberian pig as a model to clarify obscure points in the bioavailability and metabolism of ellagitannins in humans. J Agric Food Chem. 2007:55:10476-85.

38. Baati T, Horcajada P, Gref R, Couvreur P, Serre C. In vitro determination of the CYP 3 A4 activity in rat hepatic microsomes by liquid-phase extraction and HPLC-photodiode array detection. J Pharmacol Toxicol Methods. 2012; 66:29-34. https://doi.org/10.1016/j.vascn.2012.05.006.

39. Guo S, Liu Y, Lin Z, Tai S, Yin S, Liu G. Effects of Eleutheroside B and Eleutheroside $\mathrm{E}$ on activity of cytochrome $\mathrm{P} 450$ in rat liver microsomes. BMC Complement Altern Med. 2014;14:1-7.

40. Kaneko K, Suzuki K, Iwadate-Iwata E, Kato I, Uchida K, Onoue M. Evaluation of food-drug interaction of guava leaf tea. Phyther Res. 2013;27:299-305. 
41. Athukuri BL, Neerati P. Enhanced Oral bioavailability of diltiazem by the influence of Gallic acid and Ellagic acid in male Wistar rats: involvement of CYP3A and P-gp inhibition. Phyther Res. 2017;31:1441-8.

42. Kang MJ, Cho JY, Shim BH, Kim DK, Lee J. Bioavailability enhancing activities of natural compounds from medicinal plants. J Med Plants Res. 2009;3:1204-11.

43. Si D, Wang Y, Zhou YH, Guo Y, Wang J, Zhou H, et al. Mechanism of CYP2C9 inhibition by flavones and flavonols. Drug Metab Dispos. 2009;37: 629-34.

44. Le-Huu P, Heidt T, Claasen B, Laschat S, Urlacher VB. Chemo-, Regio-, and stereoselective oxidation of the monocyclic diterpenoid -cembrenediol by P450 BM3. ACS Catal. 2015;5:1772-80.

45. Tang W, Stearns RA. Heterotropic cooperativity of cytochrome P450 3A4 and potential drug-drug interactions. Curr Drug Metab. 2001;2:185-98.

46. Schoch GA, Yano JK, Wester MR, Griffin KJ, Stout CD, Johnson EF. Structure of human microsomal cytochrome P450 2C8. Evidence for a peripheral fatty acid binding site. J Biol Chem. 2004:279:9497-503.

47. Zamaratskaia G, Rasmussen MK, Škrlep M, Batorek Lukač N, Škorjanc D, Čandek-Potokar M. Tissue-specific regulation of CYP3A by hydrolysable tannins in male pigs. Xenobiotica. 2016;46:591-6.

48. Stupans L, Tan H, Kirlich A, Tuck K, Hayball P, Murray M. Inhibition of CYP3A-mediated oxidation in human hepatic microsomes by the dietary derived complex phenol, gallic acid. J Pharm Pharmacol. 2002; 54:269-75. https://doi.org/10.1211/0022357021778303.

49. Williams PA, Cosme J, Ward A, Angove HC, Matak Vinković D, Jhoti H. Crystal structure of human cytochrome P450 2C9 with bound warfarin. Nature. 2003;424:464-8.

Ready to submit your research? Choose BMC and benefit from:

- fast, convenient online submission

- thorough peer review by experienced researchers in your field

- rapid publication on acceptance

- support for research data, including large and complex data types

- gold Open Access which fosters wider collaboration and increased citations

- maximum visibility for your research: over $100 \mathrm{M}$ website views per year

At BMC, research is always in progress.

Learn more biomedcentral.com/submissions 